\title{
Two new Rahnella genomospecies that cannot be phenotypically differentiated from Rahnella aquatilis
}

\author{
Don J. Brenner, ${ }^{1}$ Hans E. Müller, ${ }^{2 \dagger}$ Arnold G. Steigerwalt, ${ }^{1}$ \\ Anne M. Whitney, ${ }^{1}$ Caroline M. O'Hara ${ }^{3}$ and Peter Kämpfer ${ }^{4}$ \\ Author for correspondence: Don J. Brenner. Tel: +1 404639 2841. Fax: +1 4046394421. \\ e-mail:djb3@cdc.gov
}

\footnotetext{
1,3 Meningitis and Special Pathogens Branch, Division of Bacterial and Mycotic Diseases', and Nosocomial Pathogens Laboratory Branch, Hospital Infections Program ${ }^{3}$, National Center for Infectious Diseases, Centers for Disease Control and Prevention, Atlanta, GA 30333, USA

2 Staatliches Medizinaluntersuchungsamt, D-38124 Braunschweig, Germany

4 Institut für Angewandte Mikrobiologie, JustusLiebig-Universität, D-

35390 Giessen, Germany
}

\begin{abstract}
Fifty-one Rahnella aquatilis and $R$. aquatilis-like strains from water, snails and human sources were characterized by routine biochemical tests, carbon source utilization tests, DNA relatedness (hydroxyapatite method) and 16S rRNA sequencing. The results of the genetic methods indicated that the strains comprised three closely related species within the genus Rahnella. It was not possible to differentiate $R$. aquatilis from the two newly recognized species. The new species were therefore given the vernacular names Rahnella genomospecies 2 and Rahnella genomospecies 3.
\end{abstract}

Keywords: Rahnella aquatilis, Rahnella aquatilis-like strains, Rahnella genomospecies, taxonomy, DNA relatedness

\section{INTRODUCTION}

During a numerical taxonomic study of the genus Enterobacter, Gavini et al. (13) used the name Group $\mathrm{H}_{2}$ for phenotypically similar, phenylalanine deaminase-positive, lysine- and ornithine-negative, arginine dihydrolase-negative strains. Subsequent DNA relatedness studies on Group $\mathrm{H}_{2}$ led Izard et al. (25) to propose the new genus and species name Rahnella aquatilis for these organisms. All the strains reported by Gavini et al. (13) were isolated from water in France. Farmer et al. (10) isolated $R$. aquatilis from water in the United States and documented the first human isolate from a burn infection (10). Subsequent reports indicated that $R$. aquatilis is widely distributed in nature $(2,19,20,23,24,36)$, present in foods $(8,17)$, and can occasionally be isolated from a variety of

† Present address: Alter Rautheimer Weg 16, D-38126 Braunschweig, Germany.

Abbreviations: pNP, para-nitrophenyl; pNA, para-nitroanilide; CDC, Centers for Disease Control and Prevention; JLU, Justus-Liebig-Universität; SM, Staatliches Medizinaluntersuchungsamt.

The GenBank accession numbers for the sequences reported in this paper are U88434-U88439, U90757 and U90758. human sources, especially from immunocompromised patients $(1,5,6,12,14,16,18,22,27-29,33,34)$.

Between 1984 and 1988, Müller et al. (30-32) cultured the intestinal contents of snails, slugs and earthworms for Enterobacteriaceae. Among the 2446 isolates obtained were a number of new species of Buttiauxella and Kluyvera, as well as other infrequently seen species, including Ewingella americana and Serratia fonticola (30-32), and nine strains that resembled $R$. aquatilis. In this report, we present the phenotypic and genotypic data used to characterize these Rahnella-like strains, as well as human and water isolates. Three DNA hybridization groups (genomospecies) were evident, one of which corresponded to $R$. aquatilis. The two new genomospecies could not be phenotypically differentiated from $R$. aquatilis with certainty and are therefore described, but not formally named.

\section{METHODS}

Bacterial strains. Fifty-one $R$. aquatilis and $R$. aquatilis-like strains were studied (Table 1). Cultures were cultivated at $30^{\circ} \mathrm{C}$ and stored on nutrient agar slants. 
Table 1. List of $R$. aquatilis and $R$. aquatilis-like strains

The following abbreviations are used in this table: CCUG, Culture Collection, University of Göteborg, Sweden; CDC, Centers for Disease Control and Prevention, USA; CUETM, Collection de l'Unité d'Ecotoxicologie Microbienne, France; DSM,

Deutsche Sammlung von Mikroorganismen und Zellkulturen GmbH, Germany; MCCM, Mannheim, Germany; SHD, State Health Department, USA; SM, Staatliches Medizinaluntersuchungsamt, Germany.

\begin{tabular}{|c|c|c|c|}
\hline Strain designation & Source & Country & Donor \\
\hline \multicolumn{4}{|l|}{ Genomospecies 1} \\
\hline CCUG 14185' (MCCM 01700; CUETM 77-115) & Water & France & W. Mannheim \\
\hline CCUG 21234 (MCCM 01659) & Not given & Not given & Not given \\
\hline CDC 5686-72 & Not given & USA & Virginia SHD \\
\hline CDC 2042-78 & Water & USA & Oregon SHD \\
\hline CDC $1327-79^{\mathrm{T}}$ (CUETM 77-115; ATCC 33071) & Water & France & H. Leclerc \\
\hline CDC 2987-79 (CUETM 78-71) & Water & France & H. Leclerc \\
\hline CDC 2989-79 (CUETM 77-143) & Water & France & H. Leclerc \\
\hline CDC 1129-80 (CUETM 77-142) & Water & France & F. Gavini \\
\hline CDC 2789-79A & Not given & Not given & Not given \\
\hline CDC 1131-80 (CUETM 78-68) & Water & France & F. Gavini \\
\hline CDC 1132-80 (CUETM 78-80) & Water & France & F. Gavini \\
\hline CDC 1133-80 (CUETM 78-85) & Water & France & F. Gavini \\
\hline CDC $1134-80$ (CUETM 78-99) & Water & France & F. Gavini \\
\hline CDC 1135-80 (CUETM 78-101) & Water & France & F. Gavini \\
\hline CDC 1136-80 (CUETM 77-133) & Water & France & F. Gavini \\
\hline CDC 742-81 & Human stool & USA & California SHD \\
\hline CDC 4301-95 & Human blood & Switzerland & G. Funke \\
\hline CDC 4591-86 & Human sputum & USA & North Carolina SHD \\
\hline DSM 4594 (CUETM 77-115) & Water & France & DSM \\
\hline DSM 30075 & Not given & Not given & DSM \\
\hline \multicolumn{4}{|l|}{ Genomospecies 2} \\
\hline CDC 301-78 & Water & USA & Georgia SHD \\
\hline CDC $301-78 \mathrm{~A}$ & Water & USA & Georgia SHD \\
\hline CDC 658-79 & Human burn & USA & North Carolina SHD \\
\hline CDC 1130-80 (CUETM 77-146) & Water & France & F. Gavini \\
\hline CCUG 21213 (MCCM 01948) & Not given & Not given & W. Mannheim \\
\hline SM Bonn 1 & Human blood* & Germany & R. Schulze-Röbbecke \\
\hline SM Bonn 3 & Human blood* & Germany & R. Schulze-Röbbecke \\
\hline SM Bonn 5 & Human blood* & Germany & R. Schulze-Röbbecke \\
\hline SM Bonn 6 & Human blood* & Germany & R. Schulze-Röbbecke \\
\hline SM Bonn 7 & Human blood* & Germany & R. Schulze-Röbbecke \\
\hline SM Bonn 9 & Human blood* & Germany & R. Schulze-Röbbecke \\
\hline SM Bonn 10 & Human blood* & Germany & R. Schulze-Röbbecke \\
\hline SM Bonn 11 & Human blood* & Germany & R. Schulze-Röbbecke \\
\hline SM Bonn 12 & Human blood* & Germany & R. Schulze-Röbbecke \\
\hline SM Bonn 13 & Human blood* & Germany & R. Schulze-Röbbecke \\
\hline SM Bonn 14 & Human blood* & Germany & R. Schulze-Röbbecke \\
\hline SM Bonn 15 & Human blood* & Germany & R. Schulze-Röbbecke \\
\hline SM Bonn 16 & Human blood* & Germany & R. Schulze-Röbbecke \\
\hline SM Bonn 17 & Human blood* & Germany & R. Schulze-Röbbecke \\
\hline SM Bremen 24 & Human & Germany & E. von Pritzbuer \\
\hline SM Hamburg 224-36 & Human & Germany & J. Bockemühl \\
\hline SM Italy 2383 & Snail & Italy & H. E. Müller \\
\hline SM SA 1224 & Snail & Germany & H. E. Müller \\
\hline SM SA 1245 & Snail & Germany & H. E. Müller \\
\hline SM S7/1-576 & Snail & Germany & H. E. Müller \\
\hline SM S7/1-682 & Snail & Germany & H. E. Müller \\
\hline SM S7/1-852 & Snail & Germany & H. E. Müller \\
\hline SM S7/1-862 & Snail & Germany & H. E. Müller \\
\hline SM S7/2-1213 & Snail & Germany & H. E. Müller \\
\hline SM S7/2-1215 & Snail & Germany & H. E. Müller \\
\hline \multicolumn{4}{|l|}{ Genomospecies 3} \\
\hline DSM 30078 & Not given & Not given & DSM \\
\hline
\end{tabular}

* Stored donated blood. 
DNA hybridization. The methods used to prepare, isolate and purify labelled and unlabelled DNA, the method used for DNA reassociation, and the method used to separate singlestranded and double-stranded DNA on hydroxyapatite have been described previously (3). DNA relatedness was determined at optimal $\left(60^{\circ} \mathrm{C}\right)$ and, on selective strains, at stringent $\left(75^{\circ} \mathrm{C}\right)$ reassociation criteria (Table 2). Percentage divergence was calculated to the nearest $0.5 \%$.

$16 \mathrm{~S}$ rRNA gene sequencing. DNA was purified as previously reported (3). Purified genomic DNA was diluted to $1 \mu \mathrm{g} \mathrm{ml}^{-1}$ in sterile water. Ten microlitres of the diluted DNA was used in a $100 \mu \mathrm{l} \mathrm{PCR}$ containing $200 \mu \mathrm{M}$ dNTPs, $1 \mathrm{mM} \mathrm{MgCl}$, $1 \times$ PCR buffer II (Perkin-Elmer), 0.1 $\mu \mathrm{M}$ fD1 primer, $0.1 \mu \mathrm{M} \mathrm{rD} 1$ primer, and $2.5 \mathrm{U}$ AmpliTaq DNA polymerase (Perkin-Elmer). The primers $\mathrm{fD} 1$ and $\mathrm{rD} 1$ were originally described by Weisburg et al. (41) as suitable for amplifying the $16 \mathrm{~S}$ gene of many eubacteria. We omitted the linker sequences from the primers as previously described (7). The parameters for the amplification were: $94{ }^{\circ} \mathrm{C}$ for $5 \mathrm{~min} ; 35$ cycles at $94{ }^{\circ} \mathrm{C}$ for $15 \mathrm{~s}, 50^{\circ} \mathrm{C}$ for $15 \mathrm{~s}$ and $72{ }^{\circ} \mathrm{C}$ for $1.5 \mathrm{~min}$; followed by a $72{ }^{\circ} \mathrm{C}$ extension for $5 \mathrm{~min}$ before cooling to $4{ }^{\circ} \mathrm{C}$.

The results of the PCR reaction were checked by running $10 \mu \mathrm{l}$ from each reaction on a $1 \%$ agarose gel. The $16 \mathrm{~S}$ DNA was then purified and concentrated by using a High Pure PCR Purification kit (Boehringer Mannheim). The concentration of the 16S PCR product was determined by using a Fluorescence Concentration Analyzer (IDEXX Laboratories). Sixty nanograms of PCR product was used for each sequencing reaction. The sequencing reaction consisted of 16S DNA, $8 \mu$ l ABI PRISM from the dye terminator cycle sequencing ready reaction kit (Perkin-Elmer) and $3.2 \mathrm{pmol}$ primer and was made up to $20 \mu \mathrm{l}$ with sterile water. The primer set used for sequencing was derived from those designed by Stackebrandt \& Charfreitag (37). The manufacturer's instructions for the cycle sequencing kit were followed for the thermal cycler conditions. The extension products from each sequencing reaction were purified through a Centrisep column (Princeton Separations) and dried in a vacuum centrifuge for $20 \mathrm{~min}$.

The sequencing reactions were resolved on a $5 \%$ acrylamide/8M urea gel electrophoresed on an ABI 373S automated sequencer (Perkin-Elmer). The sequence data were edited and compiled using the Genetics Computer Group (GCG) Sequence Analysis Package (University of Wisconsin, USA). Rahnella 16S rRNA sequences were aligned with 16S sequences from GenBank using the GCG program PILEUP and the multiple sequence file was edited by hand. The edited alignment was used in PHYLIP (version 3.5, J. Felsenstein, University of Washington, Seattle, USA) to derive a phylogenetic dendrogram using the nucleotide substitution model of Jukes \& Cantor (26) and the neighbour-joining method of Saitou \& Nei (35). The plotfile from PHYLIP 3.5 was reformatted for the HP Laserjet 4 printer with PRINTGL software (Ravitz Software).

The GenBank accession numbers for the 16S rRNA sequences are U88434-U88439, U90757 and U90758. GenBank sequences for five strains deposited as $R$. aquatilis (GenBank accession nos X79936-X79940 corresponding to strain nos 334, 2-87, 339, ATCC 33989 and 3-88, respectively) were used in the dendrogram.
Biochemical characterization. Routine biochemical tests were carried out at the Staatliches Medizinaluntersuchungsamt (SM), Braunschweig, Germany, at the Centers for Disease Control and Prevention (CDC), Georgia, USA, and at the Justus-Liebig-Universität (JLU), Giessen, Germany. At the SM, tests were done as described previously; reactions were incubated at 30 and $36^{\circ} \mathrm{C}$, and results were recorded at $48 \mathrm{~h}$ and $7 \mathrm{~d}$ (30). At $\mathrm{CDC}$, tests were done as described previously; reactions were incubated at $35^{\circ} \mathrm{C}$, unless noted (see Table 3), and results were recorded at $48 \mathrm{~h}$ and $7 \mathrm{~d}(8$, 21). At the JLU, reactions were incubated at $35^{\circ} \mathrm{C}$ and results were recorded at $48 \mathrm{~h}$ as described previously $(20,39)$. The results obtained at all institutions are shown in Table 3. Carbon source utilization tests and qualitative enzyme tests were done at the JLU using microtitre plates as described previously $(30,39)$.

\section{RESULTS \\ DNA relatedness}

DNA relatedness among $R$. aquatilis and $R$. aquatilislike strains was determined using radiolabelled DNA from the type strain of $R$. aquatilis (CDC 1327-79= CUETM 77-115 = ATCC 33071) and from two $R$. aquatilis-like strains. Three DNA relatedness groups or genomospecies were evident. The $R$. aquatilis genomospecies contained the labelled type strain (a water isolate from France), two additional cultures of the type strain from different culture collections, nine of the remaining 10 original water isolates from France, a water isolate from the United States, three human isolates and four strains of unknown origin (Table 2). Mean relatedness among these strains was $88 \%$ in $60{ }^{\circ} \mathrm{C}$ reactions, with a range of $72-100 \%$. Mean divergence within related sequences was $3.5 \%$, with a range of $0 \cdot 0-7.0 \%$, and mean relatedness in $75{ }^{\circ} \mathrm{C}$ reactions was $81 \%$, with a range of $60-100 \%$. The $R$. aquatilis type strain was $70 \%$ related, with $8 \%$ divergence, to 30 strains subsequently designated genomospecies 2 (see below) in $60^{\circ} \mathrm{C}$ reactions, and $50 \%$ related to them in $75^{\circ} \mathrm{C}$ reactions. The type strain was $64 \%$ related with $9 \%$ divergence at $60^{\circ} \mathrm{C}$ and $48 \%$ related at $75{ }^{\circ} \mathrm{C}$ to strain DSM 30078, which was subsequently designated genomospecies 3 (see below).

Labelled DNA from strain SM S7/1-576, a snail isolate, was highly related to a group of 29 strains that included the seven other snail isolates, one of the original French water isolates, two water isolates from the United States, 14 strains from contaminated stored human blood in Germany, one human isolate from the United States and four isolates of unknown origin. These strains were designated Rahnella genomospecies 2. Mean relatedness of strain SM S7/1-576 to other genomospecies 2 strains was $93 \%$ (range of $73-100 \%$ ) with mean divergence of $1.5 \%$ (range $0.5-5.5 \%$ ) in $60{ }^{\circ} \mathrm{C}$ reactions, and mean relatedness was $91 \%$ (range of $68-100 \%$ ) in $75{ }^{\circ} \mathrm{C}$ reactions. Strain SM S7/1-576 DNA showed a mean relatedness in $60^{\circ} \mathrm{C}$ reactions of 
Tab/e 2. DNA relatedness among Rahnella strains

$\% \mathrm{D}$ represents divergence, calculated to the nearest $0.5 \%$.

\begin{tabular}{|c|c|c|c|c|c|c|c|c|}
\hline \multirow{3}{*}{$\begin{array}{l}\text { Source of unlabelled } \\
\text { DNA }\end{array}$} & \multicolumn{8}{|c|}{ Relatedness (\%) to labelled DNA from: } \\
\hline & \multicolumn{3}{|c|}{ CDC $1327-79^{\mathrm{T}}$} & \multicolumn{3}{|c|}{ SM S7/1-576 } & \multicolumn{2}{|c|}{ DSM 30078} \\
\hline & $60^{\circ} \mathrm{C}$ & $\% \mathrm{D}$ & $75^{\circ} \mathrm{C}$ & $60{ }^{\circ} \mathbf{C}$ & $\% \mathrm{D}$ & $75^{\circ} \mathrm{C}$ & $60^{\circ} \mathrm{C}$ & $\% D$ \\
\hline \multicolumn{9}{|l|}{ Genomospecies 1} \\
\hline CDC $1327-79^{\mathrm{T}}$ & 100 & $0 \cdot 0$ & 100 & 55 & $8 \cdot 0$ & 46 & 53 & $11 \cdot 5$ \\
\hline $\operatorname{DSM} 4594^{\mathrm{T}}$ & 100 & $0 \cdot 0$ & 100 & 50 & $7 \cdot 5$ & 43 & & \\
\hline CCUG $14185^{\mathrm{T}}$ & 100 & $0 \cdot 0$ & 100 & 60 & $7 \cdot 5$ & 56 & & \\
\hline CDC 2987-79 & 100 & 0.5 & & 61 & $9 \cdot 5$ & 39 & & \\
\hline CDC $1135-80$ & 100 & 0.5 & 100 & 61 & $9 \cdot 5$ & 64 & & \\
\hline CDC 2789-79A & 99 & $1 \cdot 0$ & 100 & 42 & $9 \cdot 0$ & 57 & & \\
\hline CDC $5686-72$ & 93 & $2 \cdot 5$ & 92 & 58 & 8.0 & 46 & & \\
\hline DSM 30075 & 91 & $4 \cdot 0$ & 82 & 60 & $7 \cdot 5$ & 60 & & \\
\hline CDC $1136-80$ & 88 & $5 \cdot 0$ & 73 & 60 & 8.5 & 46 & 57 & $11 \cdot 0$ \\
\hline CDC $1129-80$ & 91 & $4 \cdot 5$ & 81 & 60 & $7 \cdot 5$ & 52 & & \\
\hline CDC $1132-80$ & 87 & $5 \cdot 0$ & 73 & 68 & $7 \cdot 0$ & 55 & & \\
\hline CDC $1133-80$ & 86 & $4 \cdot 5$ & 75 & 61 & $9 \cdot 0$ & 51 & 54 & $10 \cdot 5$ \\
\hline CDC $1134-80$ & 85 & $7 \cdot 0$ & 63 & 54 & $8 \cdot 5$ & 51 & 55 & $11 \cdot 0$ \\
\hline CDC 2989-79 & 83 & $1 \cdot 0$ & 97 & 47 & $8 \cdot 5$ & 44 & & \\
\hline CDC $742-81$ & 82 & $0 \cdot 0$ & 87 & 44 & $9 \cdot 0$ & 34 & & \\
\hline CDC 4591-86 & 81 & $5 \cdot 0$ & 74 & 45 & $8 \cdot 5$ & 44 & 45 & $12 \cdot 0$ \\
\hline CDC 4301-95 & 79 & $5 \cdot 0$ & 73 & 52 & 8.5 & 43 & 46 & $11 \cdot 5$ \\
\hline CDC $2042-78$ & 77 & $4 \cdot 0$ & 72 & 59 & 8.5 & 44 & 56 & $10 \cdot 5$ \\
\hline CCUG 21234 & 74 & $6 \cdot 5$ & 62 & 63 & $7 \cdot 0$ & 49 & & \\
\hline CDC $1131-80$ & 72 & $6 \cdot 0$ & 60 & 56 & $6 \cdot 5$ & 56 & & \\
\hline SM S7/1-576 & 71 & $7 \cdot 5$ & 51 & 100 & $0 \cdot 0$ & 100 & 61 & $11 \cdot 0$ \\
\hline \multicolumn{9}{|l|}{ Genomospecies 2} \\
\hline SM S7/2-1215 & 70 & $8 \cdot 5$ & 51 & 100 & 0.5 & 95 & & \\
\hline SM Bonn 15 & 76 & $9 \cdot 0$ & 50 & 100 & 0.5 & 100 & & \\
\hline SM Bonn 16 & 75 & $9 \cdot 0$ & 50 & 99 & 0.5 & 99 & & \\
\hline SM Bonn 17 & 76 & $9 \cdot 0$ & 60 & 99 & $1 \cdot 0$ & 98 & & \\
\hline SM Bremen 24 & 81 & $6 \cdot 0$ & 59 & 98 & $2 \cdot 0$ & 86 & & \\
\hline SM SA 1245 & 66 & $7 \cdot 0$ & 45 & 97 & 1.5 & 89 & & \\
\hline SM SA 1224 & 66 & $7 \cdot 0$ & 48 & 97 & 1.5 & 90 & & \\
\hline CDC 658-79 & 70 & $6 \cdot 5$ & 52 & 97 & 1.5 & 97 & & \\
\hline SM S $7 / 2-1213$ & 69 & $7 \cdot 5$ & 49 & 96 & 0.5 & 96 & & \\
\hline SM S7/1-852 & 65 & $7 \cdot 5$ & 48 & 96 & $1 \cdot 0$ & 87 & & \\
\hline CCUG 21213 & 64 & $7 \cdot 5$ & 47 & 96 & $1 \cdot 0$ & 91 & & \\
\hline SM Bonn 14 & 69 & $7 \cdot 5$ & 48 & 95 & 0.5 & 96 & & \\
\hline SM Bonn 1 & 72 & $8 \cdot 0$ & 51 & 95 & $1 \cdot 0$ & 97 & & \\
\hline SM Bonn 3 & 68 & $8 \cdot 0$ & 51 & 94 & 1.0 & 94 & & \\
\hline SM S7/1-682 & 69 & $7 \cdot 5$ & 50 & 94 & $1 \cdot 0$ & 93 & & \\
\hline SM Bonn 12 & 68 & $8 \cdot 0$ & 51 & 94 & 1.0 & 96 & & \\
\hline SM Bonn 7 & 70 & $7 \cdot 5$ & 45 & 93 & $1 \cdot 0$ & 95 & & \\
\hline SM Bonn 6 & 65 & $8 \cdot 0$ & 48 & 93 & $1 \cdot 0$ & 92 & & \\
\hline SM Bonn 9 & 68 & $8 \cdot 0$ & 49 & 93 & 1.0 & 94 & & \\
\hline SM Bonn 5 & 66 & $8 \cdot 0$ & 45 & 92 & $1 \cdot 0$ & 92 & & \\
\hline SM Bonn 11 & 71 & $7 \cdot 5$ & 50 & 92 & 1.5 & 94 & & \\
\hline SM Bonn 13 & 72 & 8.0 & 51 & 91 & 0.5 & 95 & & \\
\hline SM S7/1-862 & 73 & $8 \cdot 0$ & 49 & 91 & $1 \cdot 0$ & 91 & & \\
\hline SM Bonn 10 & 68 & 8.0 & 46 & 90 & 1.0 & 91 & & \\
\hline SM Hamburg 224-36/89 & 66 & $8 \cdot 0$ & 45 & 89 & 1.5 & 83 & & \\
\hline CDC $301-78^{\circ}$ & 67 & $6 \cdot 0$ & 56 & 83 & $2 \cdot 0$ & 78 & & \\
\hline CDC $301-78 \mathrm{~A}$ & 75 & $8 \cdot 5$ & 46 & 82 & 1.5 & 90 & & \\
\hline SM Italy 2383 & 68 & $8 \cdot 0$ & 47 & 74 & $5 \cdot 0$ & 68 & 55 & $11 \cdot 0$ \\
\hline CDC $1130-80$ & 76 & $9 \cdot 5$ & 49 & 70 & $5 \cdot 5$ & 74 & 49 & 11.0 \\
\hline \multicolumn{9}{|l|}{ Genomospecies 3} \\
\hline DSM 30078 & 64 & $9 \cdot 0$ & 48 & 53 & $9 \cdot 0$ & 39 & 100 & $0 \cdot 0$ \\
\hline
\end{tabular}


$56 \%$, with $8 \%$ divergence, to DNAs from the 20 strains in the $R$. aquatilis genomospecies. Mean relatedness to these strains in $75^{\circ} \mathrm{C}$ reactions was $49 \%$. Relatedness of strain SM S7/1-576 to strain DSM 30078 was $48 \%$ with $11 \%$ divergence at $60^{\circ} \mathrm{C}$.

Labelled DNA from strain DSM 30078 was $53 \%$ related to the type strain of $R$. aquatilis, with related sequences exhibiting $11 \%$ divergence. Its mean relatedness to six other $R$. aquatilis (sensu stricto) strains was $52 \%$ with $11 \%$ divergence. Relatedness of DSM 30078 to the reference strain of Rahnella genomospecies 2 was $61 \%$ with $11 \%$ divergence. DSM 30078 showed $52 \%$ relatedness, with $11 \%$ divergence, to two other strains from genomospecies 2. Since DSM 30078 was not related at the species level to either $R$. aquatilis or to Rahnella genomospecies 2, it was designated Rahnella genomospecies 3 .

\section{S rRNA sequencing}

Eight representative strains from the three Rahnella hybridization groups were used for 16S rRNA gene amplification and sequencing: CDC 2987-79, CDC 1327-79, DSM 30078, SM Bonn 7, SM S7/1-576, SM Italy 2383, CDC $658-79$ and CCUG 21234 . The $16 \mathrm{~S}$ sequences were aligned and edited. The hypervariable regions V1 and V5 were omitted (15), resulting in a sequence that corresponded to Escherichia coli base positions 147-1490 (4). The dendrogram derived from the distance matrix is shown in Fig. 1.

The eight Rahnella strains fell into three distinct groups (Fig. 1). The $R$. aquatilis type strain group contained five strains: CDC 2987-77 and CDC 1327-79 and three $R$. aquatilis sequences previously deposited in GenBank, which were $99 \cdot 70-100.00 \%$ similar to each other. The second group contained a total of seven strains: SM Bonn 7, SM S7/1-576, SM Italy 2383, CDC 658-79, CCUG 21234, and two sequences retrieved from GenBank that had been deposited as $R$. aquatilis, which were $99 \cdot 40-99.92 \%$ similar to each other, and $97.77-98.37 \%$ similar to the $R$. aquatilis type strain group. The third group contained only strain DSM 30078, which was 98-29-98.58\% similar to the other Rahnella genomospecies.

\section{Routine biochemical characterization}

The biochemical test results for strains assigned to $R$. aquatilis (GS 1) and to GS 2 and GS 3 were obtained independently in three laboratories. The data obtained at CDC (9) are shown in Table 3. Agreement of results obtained in the three laboratories was generally good, and results obtained for GS 1 strains were in close agreement with previously published biochemical profiles of $R$. aquatilis $(10,13)$. For GS 1, different results were obtained for ornithine decarboxylase $(0 \%$ at CDC, $50 \%$ at SM) and methyl $\alpha$-D-glucoside $(0 \%$ at $\mathrm{CDC}, 25 \%$ at SM, and $75 \%$ at JLU). For GS 2, methyl $\alpha$-D-glucoside was $0 \%$ at CDC and JLU, and $70 \%$ at SM. A number of discrepancies was seen in reactions for the single strain (DSM 30078) in GS 3. This strain was methyl red-positive, citrate-negative, phenylalanine deaminase-negative, did not produce gas from D-glucose and was acetate-negative in tests at CDC, whereas the opposite results were obtained at SM (phenylalanine deaminase was delayed positive). In tests for acid production from carbohydrates, DSM 30078 was cellobiose-negative at CDC (positive at SM and JLU), raffinose-positive at CDC and JLU (negative at SM), and L-rhamnose-negative at CDC (positive at SM and JLU). GS 1 and GS 2 could not be differentiated on the basis of this battery of biochemical tests. GS 3 could be differentiated from GS 1 and GS 2 on the basis of its positive D-arabitol reaction and its negative dulcitol reaction.

\section{Carbon source utilization and hydrolysis tests}

Strains were tested for their ability to utilize a battery of carbohydrates and to hydrolyse a battery of substrates (Table 3). No test or test battery served to differentiate GS 1 and GS 2 strains. A combination of utilization of L-histidine, L-ornithine and L-proline, and hydrolysis of L-proline-pNA appears to be helpful. GS 3 is separable from GS 1 and GS 2 strains on the basis of its negative reactions in tests for the utilization of DL-lactate and L-glutamate- $\tau$-3-carboxy-pNA.

\section{DISCUSSION}

Since its recognition from water isolates in 1976 (13) and its description in 1979 (25), R. aquatilis has been isolated from a relatively large number of environmental and human sources $(1,2,5,6,8,10,12,14$, $16-20,22-24,27-29,33,34,36)$. Our isolates from snails enlarge its habitat still further. Our DNA relatedness studies were designed to confirm the identity of these and other unusual isolates from molluscs. To our surprise, strains with the biochemical profile of $R$. aquatilis were in three separate DNA relatedness groups or genomospecies.

GS 1 consisted of 20 strains, including three separate cultures of the $R$. aquatilis type strain. It therefore corresponded to $R$. aquatilis. Seventeen of these strains conformed fully to the molecular definition of a bacterial species as a group of strains whose DNAs share at least $70 \%$ relatedness at optimal criteria for DNA reassociation $\left(60^{\circ} \mathrm{C}\right.$ reactions in this study), and whose related sequences show $5 \%$ or less divergence (40). The three remaining strains in GS 1, CDC 113480 , CCUG 21234 and CDC 1131-80, were $72-85 \%$ related to the type strain of $R$. aquatilis, with divergence within related sequences of $6.0-7 \cdot 0 \%$. Their relatedness to the type strain of $R$. aquatilis at stringent reassociation criteria $\left(75^{\circ} \mathrm{C}\right.$ reactions in this study) was $60-63 \%$. In our laboratory, we consider $60 \%$ or greater relatedness at stringent reassociation criteria to also represent species level relatedness. We tend to place strains that fulfil at least two of the three criteria for species level relatedness within the species. Re- 
Table 3. Reactions of $R$. aquatilis and $R$. aquatilis-like strains in routine biochemical tests

All strains gave positive reactions within $48 \mathrm{~h}$ in tests for fermentation of L-arabinose, $\mathrm{D}$ galactose, D-glucose, lactose, D-mannitol, ONPG, salicin and trehalose, and in the test for nitrate reduction. All strains gave negative reactions after $7 \mathrm{~d}$ in tests for fermentation of adonitol, erythritol and iso-inositol, and in tests for DNase, hydrogen sulfide, indole production, oxidase, tyrosine deaminase, urease and yellow pigment. All strains gave positive reactions in tests for utilization of $N$-acetyl-D-glucosamine, L-arabinose, $p$-arbutin, D-cellobiose, D-galactose gluconate, D-glucose, D-maltose, D-mannose, $\alpha$-D-melibiose, L-rhamnose, D-ribose, salicin, D-trehalose, Dxylose, D-mannitol, D-sorbitol, citrate, fumarate, L-malate, pyruvate and L-serine, and positive reactions in tests for hydrolysis of pNP- $\beta$-D-xylopyranoside, bis-pNP-phosphate, pNP-phenylphosphonate, pNP-phosphoryl choline and L-alanine-pNA. All strains gave negative reactions in tests for utilization of adonitol, iso-inositol, putrescine, propionate, adipate, azelate, glutarate, DL-3-hydroxybutyrate, mesaconate, suberate, $\beta$-alanine, L-leucine, L-tryptophan, 3 -

hydroxybenzoate and 4-hydroxybenzoate. + , Positive reaction; - , negative reaction; $(+)$, delayed (3-7 d) positive reaction; numbers indicate the percentage of strains giving a positive reaction within $48 \mathrm{~h}$; numbers in parentheses indicate the percentage of strains giving a positive reaction within $7 \mathrm{~d}$. pNP, para-nitrophenyl; pNA, para-nitroanilide.

\begin{tabular}{|c|c|c|c|}
\hline Biochemical reaction & GS 1 & GS 2 & GS 3 \\
\hline Methyl red & 89 & 52 & + \\
\hline Voges-Proskauer & 100 & 72 & + \\
\hline Citrate utilization & $83(94)$ & $48(79)$ & - \\
\hline Phenylalanine deaminase & 94 & 72 & + \\
\hline Arginine dihydrolase & 0 & $0(3)$ & - \\
\hline Lysine decarboxylase & 0 & 0 & - \\
\hline Ornithine decarboxylase & $0(11)$ & 0 & - \\
\hline Motility & $33(44)$ & $24(31)$ & - \\
\hline Gelatin liquefaction $\left(22^{\circ} \mathrm{C}\right)$ & $0(6)$ & $0(34)$ & - \\
\hline $\mathrm{KCN}$, growth & $0(11)$ & 3 & - \\
\hline Malonate & 89 & $52(79)$ & + \\
\hline Gas from D-glucose & 83 & 76 & - \\
\hline \multicolumn{4}{|l|}{ Acid from: } \\
\hline D-Arabitol & 0 & 3 & + \\
\hline Cellobiose & 100 & $90(93)$ & + \\
\hline Dulcitol & $89(94)$ & $76(83)$ & - \\
\hline Maltose & 100 & $90(100)$ & + \\
\hline D-Mannose & 100 & 100 & + \\
\hline Melibiose & $94(100)$ & 100 & + \\
\hline Methyl $\alpha$-D-glucoside & 0 & 0 & - \\
\hline Raffinose & 94 & 97 & + \\
\hline L-Rhamnose & 100 & 100 & - \\
\hline D-Sorbitol & 94 & 97 & + \\
\hline Sucrose & 100 & 97 & + \\
\hline D-Xylose & 100 & 100 & $(+)$ \\
\hline Glycerol & $0(56)$ & $7(34)$ & - \\
\hline Aesculin hydrolysis & 100 & 97 & + \\
\hline Mucate & $28(44)$ & 0 & - \\
\hline Tartrate & 33 & 86 & + \\
\hline Acetate & 11 & 3 & - \\
\hline Lipase (corn oil) & 0 & 0 & - \\
\hline Lipase (Tween 80) & 75 & 63 & - \\
\hline \multicolumn{4}{|l|}{ Utilization of: } \\
\hline$N$-Acetyl-D-galactosamine & 0 & 4 & - \\
\hline D-Fructose & 75 & 65 & + \\
\hline D-Sucrose & 100 & 96 & + \\
\hline Acetate & 0 & 27 & - \\
\hline cis-Aconitate & 25 & 15 & - \\
\hline trans-Aconitate & 0 & 4 & - \\
\hline
\end{tabular}


Table 3 (cont.)

\begin{tabular}{|lrrc|}
\hline Biochemical reaction & GS 1 & GS 2 & GS 3 \\
\hline 4-Aminobutyrate & 0 & 4 & - \\
DL-Lactate & 100 & 96 & - \\
2-Oxoglutarate & 25 & 4 & - \\
L-Alanine & 100 & 73 & + \\
L-Aspartate & 100 & 92 & + \\
L-Histidine & 50 & 8 & + \\
L-Ornithine & 50 & 0 & - \\
L-Phenylalanine & 0 & 4 & - \\
L-Proline & 50 & 4 & - \\
Phenylacetate & 0 & 4 & - \\
Hydrolysis of: & & & \\
pNP- $\beta$-D-galactopyranoside & 0 & 8 & - \\
pNP- $\alpha$-D-glucopyranoside & 25 & 4 & - \\
pNP- $\beta$-D-glucopyranoside & 100 & 12 & + \\
2-Deoxythymidine-5'-pNP-phosphate & 0 & 12 & - \\
L-Glutamate- $\tau$-3-carboxy-pNA & 100 & 85 & - \\
L-Proline-pNA & 75 & 4 & + \\
\hline
\end{tabular}

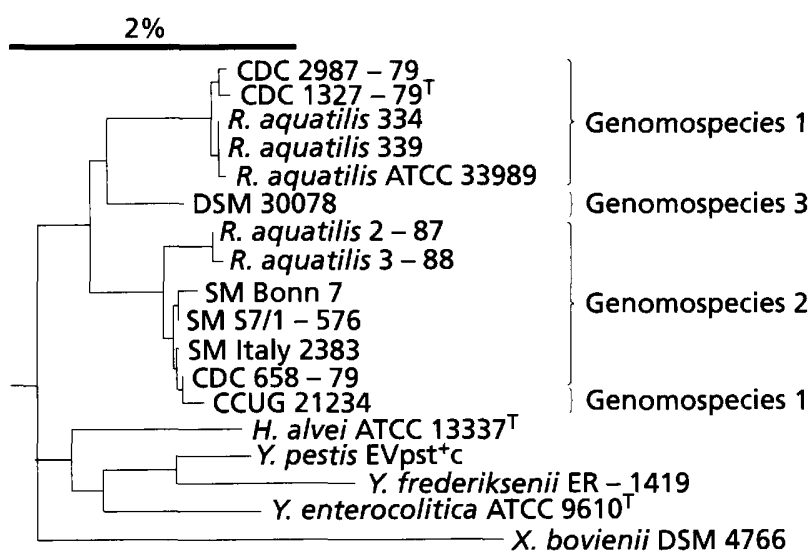

Fig. 1. Phylogenetic dendrogram based on a neighbour-joining comparison of a 1350 nucleotide 16S rRNA gene sequence. The scale bar represents a $2 \%$ difference. The accession numbers for the sequences retrieved from GenBank are: X79936, $R$. aquatilis $334 ; X 79937, R$. aquatilis $2-87 ; X 79938, R$. aquatilis $339 ; X 79939$, $R$. aquatilis ATCC 33989; X79940, $R$. aquatilis 3-88; M59155, Hafnia alvei; M59292, Yersinia enterocolitica; 275317, Yersinia pestis; X75273, Yersinia frederiksenii; X82252, Xenorhabdus bovienii. The accession numbers for the strains sequenced in this study are: U88436, CDC 2987-79; U90757, CDC 1327-79; U90758, DSM 30078; U88438, SM Bonn 7; U88434, SM s7/1-576; U88439, SM Italy 2383; U88437, CDC 658-79; U88435, CCUG 21234. The sequence of CCUG 21234 (genomospecies 1) clusters with the strains in genomospecies 2 .

ciprocal DNA relatedness tests using type or reference strains for GS 1 and GS 2 and a stringent, $75^{\circ} \mathrm{C}$ incubation temperature serve to separate all strains placed in these genomospecies. It is possible that strains CCUG 21234 and CDC 1131-80 represent a fourth Rahnella genomospecies. However, for the reasons stated above, and for convenience pending study of further strains, these strains were provisionally included in GS 1.

Thirty strains were placed in GS 2. All but two of these were $83 \%$ or more related with $2 \%$ or less divergence within related sequences. The two other strains were at the border of species level relatedness $(73-74 \%$ relatedness at $60{ }^{\circ} \mathrm{C}, 5 \cdot 0-5 \cdot 5 \%$ divergence, and 68-74\% relatedness at $75^{\circ} \mathrm{C}$ ) and were included in GS 2. All 14 Bonn strains were isolated from contaminated stored blood. It is possible that they represented multiple isolates of a single strain. If this were true, their inclusion does not significantly skew the data since almost all other GS 2 strains show comparable levels of relatedness to the labelled GS 2 reference strain, as do the Bonn strains.

Mean relatedness of the $20 \mathrm{GS} 1$ strains to labelled DNA from a GS 2 strain in $60^{\circ} \mathrm{C}$ reactions was $56 \%$ with $8 \%$ divergence. In reciprocal reactions at $60{ }^{\circ} \mathrm{C}$, GS 2 strains were $64-81 \%$ ( $70 \%$ mean) related to labelled DNA from GS 1; however, the mean divergence was $8 \%$. Relatedness of each of these strains to labelled DNA from a GS 2 strain was significantly higher, and divergence was significantly lower. In $75^{\circ} \mathrm{C}$ reactions, GS 1 strains were $81 \%$ interrelated compared to $48 \%$ relatedness to GS 2 strains. Reciprocally, GS 2 strains were $91 \%$ interrelated at $75^{\circ} \mathrm{C}$, compared to $49 \%$ relatedness to GS 1 strains. We therefore felt justified in designating the GS 1 and GS 2 strains as separate species. One strain, DSM 30078 , was not related to either GS 1 or GS 2 at the species level. It was therefore designated GS 3.

One of the two strains (CCUG 21234) provisionally 
placed in GS 1 was sequenced. It grouped in GS 2 , showing $98 \cdot 06-98 \cdot 14 \%$ similarity to GS 1 strain sequences and $99 \cdot 18-99 \cdot 85 \%$ similarity to GS 2 strain sequences. It is possible that its grouping at the species level on the basis of sequence is misleading, as has been seen on several occasions with other genera $(11,38)$. Perhaps the grouping of CCUG 21234 with GS 2 strains indicates a back-mutation or recombinational event in the 16S rRNA gene. The more likely of these two possibilities is the recombinational event. In a 26 base region beginning at position 454 [E. coli numbering system (4)] the GS 1 strains differ from the GS 2 strains by nine bases. Strain CCUG 21234 is $100 \%$ homologous to all of the GS 2 strains in this variable region.

The level of relatedness, in excess of $40 \%$, between the three genomospecies was compatible with placing them in the single genus Rahnella. This conclusion was strongly confirmed by their high level of $16 \mathrm{~S}$ rRNA similarity and supported by their extremely similar biochemical profiles. 16S rRNA sequence studies confirmed the existence of three phylogenetic groups within the test strains and similar strains whose sequences had previously been deposited in GenBank. Further, the close relatedness between the sequences of the three 16S rRNA groups confirmed that they all were most closely related to one another and should remain in the single genus Rahnella. GS 1 corresponds to $R$. aquatilis, GS 2 should be referred to as Rahnella genomospecies 2 and GS 3 should be referred to as Rahnella genomospecies 3 .

It should be noted that the five strain sequences previously deposited in the GenBank were all called $R$. aquatilis. The type strain was not included, and similarity values among the strains were 97.84$100.00 \%$. Two of these strains, $2-87$ and 3-88, group with our GS 2 strains $(99 \cdot 40-99 \cdot 55 \%$ similarity). This observation again points out the fact that, while sequence differences of more than $3 \%$ are sufficient to exclude a strain from a species, it is prudent to do DNA hybridization on strains exhibiting $97 \%$ or greater sequence similarity before concluding that they belong to the same species $(11,38)$.

It was not possible to identify GS 1 and GS 2 solely on the basis of their biochemical characteristics. It appeared that GS 3 could be identified biochemically but, since only one GS 3 strain is known, this observation is tentative. We hesitate to formally name genomospecies that cannot be differentiated biochemically. We therefore refer to them as Rahnella genomospecies 2 and Rahnella genomospecies 3 .

Isolates from a variety of human sources have been identified as $R$. aquatilis. On the basis of our DNA relatedness data, we know that some of these strains were actually Rahnella genomospecies 2 . Molecular identification of all clinical isolates would be required to attempt a determination of the relative clinical incidence and significance of $R$. aquatilis and Rahnella genomospecies 2 . We do not know the source of the Rahnella genomospecies 3 strain.

\section{REFERENCES}

1. Alaallaa, S. R., Qadri, S. M. H., Al-Furayh, O. \& Al-Qatary, K. (1992). Urinary tract infection due to Rahnella aquatilis in a renal transplant patient. J Clin Microbiol 30, 2948-2950.

2. Berge, O., Heulin, T., Achouak, W., Richard, C., Bally, R. \& Balandreau, J. (1991). Rahnella aquatilis, a nitrogen-fixing enteric bacterium associated with the rhizosphere of wheat and maize. Can J Microbiol 37, 195-203.

3. Brenner, D. J., McWhorter, A. C., Leete-Knutson, J. K. \& Steigerwalt, A. G. (1982). Escherichia vulneris: a new species of Enterobacteriaceae associated with human wounds. $J$ Clin Microbiol 15, 1133-1140.

4. Brosius, J., Palmer, M. L., Kennedy, P. J. \& Noller, H. F. (1978). Complete nucleotide sequence of a $16 \mathrm{~S}$ ribosomal RNA gene from Escherichia coli. Biochem 75, 4801-4805.

5. Caraccio, V., Rocchetti, A. \& Garavelli, P. L. (1994). Rahnella aquatilis bacteremia in a patient with chronic renal failure. G Mal Infett Parassit 46, 330-331.

6. Christiaens, E., Hansen, W. \& Moinet, J. (1987). Isolement des expectorations d'un patient atteint de leucemie lymphoide chronique et de broncho-emphysème d'une Enterobacteriaceae nouvellement décrite: Rahnella aquatilis. Med Mal Infect 17, 732-734.

7. Daly, J. S., Worthington, M. G., Brenner, D. J., Moss, C. W., Hollis, D. G., Weyant, R. S., Steigerwalt, A. G., Weaver, R. E., Daneshvar, M. I. \& O'Connor, S.P. (1993). Rochalimaea elizabethae sp. nov. isolated from a patient with endocarditis. J Clin Microbiol 31, 872-881.

8. Davis, J. A. \& Eyles, M. J. (1992). Discolouration of cottage cheese caused by Rahnella aquatilis in the presence of glucono- $\delta$-lactone. Aust J Dairy Technol 47, 62-63.

9. Farmer, J. J., III, Asbury, M. A., Hickman, F. W., Brenner, D. J. $\&$ the Enterobacteriaceae Study Group (1980). Enterobacter sakazakii: a new species of 'Enterobacteriaceae' isolated from clinical specimens. Int J Syst Bacteriol 30, 569-584.

10. Farmer, J. J., III, Davis, B. R., Hickman-Brenner, F. W. \& 12 other authors (1985). Biochemical identification of new species and biogroups of Enterobacteriaceae isolated from clinical specimens. J Clin Microbiol 21, 46-76.

11. Fox, G. E., Wisotzkey, J. D. \& Jurtshuk, P., Jr (1992). How close is close: $16 \mathrm{~S}$ rRNA sequence identity may not be sufficient to guarantee species identity. Int $J$ Syst Bacteriol 42, 166-170.

12. Funke, G. \& Rosner, H. (1995). Rahnella aquatilis bacteremia in an HIV-infected intravenous drug abuser. Diagn Microbiol Infect Dis 22, 293-296.

13. Gavini, F., Ferragut, C., Lefebvre, B. \& Leclerc, H. (1976). Étude taxonomique d'entérobactéries appartenant ou apparentées au genre Enterobacter. Ann Microbiol (Paris) 127B, 317-335.

14. Geiges, O., Staehlin, B. \& Baumann, B. (1990). The microbiological evaluation of prepared salad vegetables and sprouts. Mitt Geb Lebensmittelunters Hyg 81, 684-721.

15. Gray, M. W., Sankoff, D. \& Cedergren, R. J. (1984). On the evolutionary descent of organisms and organelles: a global phylogeny based on a highly conserved structural core in a small subunit ribosomal RNA. Nucleic Acids Res 12 , $5837-5852$. 
16. Goubau, P., Van Aelst, F., Verhaegen, J. \& Boogaerts, M. (1988). Septicaemia caused by Rahnella aquatilis in an immunocompromised host. Eur J Clin Microbiol Infect Dis 7, 697-699.

17. Hamze, M., Mergaert, J., van Vuuren, H. J., Gavini, F., Beji, A., Izard, D. \& Kersters, K. (1991). Rahnella aquatilis, a potential contaminant in lager beer breweries. Int $J$ Food Microbiol 13, 63-68.

18. Harrell, L. J., Cameron, M. L. \& O'Hara, C. M. (1989). Rahnella aquatilis, an unusual Gram-negative rod isolated from the bronchial washing of a patient with acquired immunodeficiency syndrome. J Clin Microbiol 27, 1671-1672.

19. Heron, S. J. E., Wilkinson, J. F. \& Duffus, C. M. (1993). Enterobacteria associated with grass and silages. $J$ Appl Bacteriol 75, 13-17.

20. Heulin, T., Berge, O., Mavingui, P., Gouzou, L., Hebbar, K. P. \& Balandreau, J. (1994). Bacillus polymyxa and Rahnella aquatilis, the dominant $\mathrm{N}_{2}$-fixing bacteria associated with wheat rhizosphere in French soils. Eur J Soil Biol 30, 35-42.

21. Hickman, F. W. \& Farmer, J. J., III (1978). Salmonella typhi: identification, antibiograms, serology, and bacteriophage typing. Am J Med Technol 44, 1149-1159.

22. Hoppe, J.E., Herter, M., Aleksic, S., Klingebiel, T. \& Niethammer, D. (1993). Catheter-related Rahnella aquatilis bacteremia in a pediatric bone marrow transplant recipient. $J$ Clin Microbiol 31, 1911-1912.

23. Horie, S., Yanagida, Y., Saheki, K., Hiraishi, A. \& Cho, C. (1985). Occurrence of Rahnella aquatilis psychrotrophic coliforms in mountain soils. J Food Hyg Soc Jpn 26, 573-578.

24. limura, K. \& Hosono, A. (1996). Biochemical characteristics of Enterobacter agglomerans and related strains found in buckwheat seeds. Int J Food Microbiol 30, 243-253.

25. Izard, D., Gavini, F., Trinel, P. A. \& Leclerc, H. (1979). Rahnella aquatilis, nouveau membre de la famille des Enterobacteriaceae. Ann Microbiol (Paris) 130, 163-177.

26. Jukes, T. H. \& Cantor, C. R. (1969). Evolution of protein molecules. In Mammalian Protein Metabolism, vol. 3, pp. 21-132. Edited by H. N. Monro. New York: Academic Press.

27. Lebessi, E., Paraskaki, I., Grigoraki, K., Cosmidis, H. \& Deliyianni, V. (1990). Rahnella aquatilis: saprophytic or opportunistic pathogenic bacterium. Acta Microbiol Hell 35, 569-574

28. Maraki, S., Samonis, G., Marnelakis, E. \& Tselentis, Y. (1994). Surgical wound infection caused by Rahnella aquatilis. $J$ Clin Microbiol 32, 2706-2708.

29. Matsukura, H., Katayama, K., Kitano, N., Kobayashi, K., Kanegane, C., Higuchi, A. \& Kyotani, S. (1996). Infective endocarditis caused by an unusual gram-negative rod, Rahnella aquatilis. Pediatr Cardiol 17, 108-111.

30. Müller, H. E., Brenner, D. J., Fanning, G. R., Grimont, P. A. D. \& Kämpfer, P. (1996). Emended description of Buttiauxella agrestis with recognition of six new species of Buttiauxella and two new species of Kluyvera: Buttiauxella ferragutiae sp. nov., Buttiauxella gaviniae sp. nov., Buttiauxella brennerae sp. nov., Buttiauxella izardii sp. nov., Buttiauxella noackiae sp. nov., Buttiauxella warmboldiae sp. nov., Kluyvera cochleae sp. nov., and Kluyvera georgiana sp. nov. Int J Syst Bacteriol 46, 50-63.

31. Müller, H. E., Fanning, G. R. \& Brenner, D. J. (1995). Isolation of Ewingella americana from mollusks. Curr Microbiol 31, 287-290.

32. Müller, H. E., Fanning, G. R. \& Brenner, D. J. (1995). Isolation of Serratia fonticola from mollusks. Syst Appl Microbiol 18, 279-284.

33. Oh, H. M. \& Tay, L. (1995). Bacteremia caused by Rahnella aquatilis: report of two cases and review. Scand $J$ Infect Dis 27, 79-80.

34. Reina, J. \& Lopez, A. (1996). Clinical and microbiological characteristics of Rahnella aquatilis strains isolated from children. $J$ Infect 33, 135-137.

35. Saitou, N. \& Nei, M. (1987). The neighbor-joining method: a new method for reconstructing phylogenetic trees. Mol Biol Evol 4, 406-425.

36. Selenska-Pobell, S., Evguenieva-Hackenberg, E. \& Schwickerath, 0 . (1995). Random and repetitive primer amplified polymorphic DNA analysis of five soil and two clinical isolates of Rahnella aquatilis. Syst Appl Microbiol 18, 425-438.

37. Stackebrandt, E. \& Charfreitag, O. (1990). Partial 16S rRNA primary structure of five Actinomyces species: phylogenetic implications and development of an Actinomyces israeliispecific oligonucleotide probe. J Gen Microbiol 136, 37-43.

38. Stackebrandt, E. \& Goebel, B. M. (1994). Taxonomic note: a place for DNA-DNA reassociation and $16 \mathrm{~S}$ rRNA sequence analysis in the present species definition in bacteriology. Int J Syst Bacteriol 44, 846-849.

39. Véron, M. (1975). Nutrition et taxonomie des enterobactéries. I. Methode d'étude des auxanogrammes. Ann Microbiol (Paris) 126A, 267-274.

40. Wayne, L. G., Brenner, D. J., Colwell, R. R. \& 9 other authors (1987). International Committee on Systematic Bacteriology. Report of the Ad Hoc Committee on reconciliation of approaches to bacterial systematics. Int J Syst Bacteriol 37, 463-464.

41. Weisburg, W. G., Barns, S. M., Pelletier, D. A. \& Lane, D. J. (1991). 16S ribosomal DNA amplification for phylogenetic study. J Bacteriol 173, 697-703. 